\title{
Characterisation and microleakage of a new hydrophilic fissure sealant - UltraSeal XT ${ }^{\circledR}$ hydro ${ }^{\mathrm{TM}}$
}

\author{
Zeynep A. GÜÇLÜ', Nazmiye DÖNMEZ², Andrew P. HURT ${ }^{3}$, Nichola J. COLEMAN ${ }^{3}$
}

\author{
1- Erciyes Üniversitesi, Diş Hekimliği Fakültesi Pedodonti, Kayseri, Turkey. \\ 2- Bezmialem Vakıf Üniversitesi, Diş Hastalıkları ve Tedavisi, İstanbul, Turkey. \\ 3- University of Greenwich, Faculty of Engineering and Science, Kent, United Kingdom.
}

Corresponding address: Nichola J. Coleman - Faculty of Engineering and Science, University of Greenwich - Chatham Maritime - Kent - ME4 4TB - United Kingdom - Phone: +44 (0)7980 017088 - e-mail: nj_coleman@yahoo.co.uk

Submitted: January 24, 2016 - Modification: March 31, 2016 - Accepted: May 6, 2016

\section{ABSTRACT}

$\mathrm{O}$ bjectives: The aim of this study was to characterise the new hydrophilic fissure sealant, UltraSeal $\mathrm{XT}^{\circledR}{ }^{\circledR}$ hydro ${ }^{\mathrm{TM}}$ (Ultradent Products, USA), and to investigate its in vitro resistance to microleakage after placement on conventionally acid etched and sequentially lased and acid etched molars. Material and Methods: The sealant was characterised by Fourier transform infra-red spectroscopy (FTIR), scanning electron microscopy (SEM), energy dispersive X-ray analysis (EDX), and Vickers indentation test. Occlusal surfaces of extracted human molars were either conventionally acid etched $(n=10)$, or sequentially acid etched and laser irradiated $(n=10)$. UltraSeal $X T^{\oplus}$ hydro ${ }^{T M}$ was applied to both groups of teeth which were then subjected to 2,500 thermocycles between 5 and $55^{\circ} \mathrm{C}$ prior to microleakage assessment by fuchsin dye penetration. Results: UltraSeal $\mathrm{XT}^{\circledR}{ }^{\circledR}$ hydro ${ }^{\mathrm{TM}}$ is an acrylate-based sealant that achieved a degree of conversion of $50.6 \pm 2.2 \%$ and a Vickers microhardness of $24.2 \pm 1.5$ under standard light curing $\left(1,000 \mathrm{mWcm}^{-2}\right.$ for $\left.20 \mathrm{~s}\right)$. Fluoride ion release is negligible within a 14-day period. SEM and EDX analyses indicated that the sealant comprises irregular submicron and nano-sized silicon-, barium-, and aluminium-bearing filler phases embedded in a ductile matrix. Laser preconditioning was found to significantly reduce microleakage (Mann-Whitney $U$ test, $p<0.001$ ). The lased teeth presented enhanced surface roughness on a 50 to $100 \mu \mathrm{m}$ scale that caused the segregation and concentration of the filler particles at the enamel-sealant interface. Conclusion: Laser preconditioning significantly decreased microleakage and increased enamel surface roughness, which caused zoning of the filler particles at the enamel-sealant interface.

Keywords: Hydrophilic. Fissure sealants. Er:YAG lasers. Microleakage. Microhardness.

\section{NTRODUCTI ON}

Approximately $90 \%$ of all dental caries arise in the occlusal pits and fissures, since these regions are anatomically defended against the remineralising flow of saliva and routine brushing ${ }^{8}$. Accordingly, resin-based or glass ionomer sealants are placed over the occlusal surfaces of premolars and molars to prevent cariogenic microorganisms and fermentable organic debris from accumulating in the pits and fissures ${ }^{11}$.

The majority of commercially available resinbased pit and fissure sealants are hydrophobic materials that bond to the enamel surface via micromechanically interlocking tags ${ }^{13}$. The presence of moisture and saliva-contamination during the placement of the sealant compromise the quality of adhesion at the sealant-enamel interface, which impacts the ongoing resistance to microleakage of microorganisms. Recently introduced hydrophilic sealants, which bond effectively to moist enamel surfaces, present a distinct advantage in paediatric dentistry where patient-compliance, isolation, and moisture-control can be particularly challenging ${ }^{10}$.

UltraSeal $X^{\oplus}{ }^{\oplus}$ hydro $^{\text {TM }}$ is a new moisturetolerant, self-adhesive, light-cured, acrylate-based, hydrophilic pit, and fissure sealant which has been developed by Ultradent Products, USA ${ }^{4}$. The sealant comprises a $53 \mathrm{wt} \%$ mixture of inorganic filler particles that confer radiopacity. This material 
is reported to "chase" moisture into the pits and fissures, thus eliminating moisture-related failure associated with hydrophobic sealants ${ }^{4}$.

Prior to the application of a resin-based fissure sealant, the enamel surface is etched with phosphoric acid gel to enhance surface roughness and wettability and to increase porosity and surface area available for bonding ${ }^{1}$. Recent research has indicated that the application of laser ablation as an adjunct to phosphoric acid etching may improve the adhesion, marginal adaptation, retention, and resistance to microleakage of resin-based sealants ${ }^{10}$. This finding is not universal, and the efficacy of laser conditioning appears to depend upon the rheological and physicochemical properties of different sealants ${ }^{3,5,12}$. It is suggested that less viscous, more "flowable" materials may afford better adaptation to the rougher surfaces presented by lased enamel ${ }^{9}$.

The objectives of this study were to characterise the new hydrophilic sealant, UltraSeal $X T^{\circledR}{ }^{~ h y d r o ~}{ }^{\mathrm{Tm}}$, and to investigate its resistance to microleakage in vitro. The chemical composition and degree of curing of UltraSeal $\mathrm{XT}^{\circledR}$ hydro ${ }^{\mathrm{m}}$ were investigated by Fourier transform infra-red spectroscopy (FTIR). Scanning electron microscopy (SEM) was used to examine the fracture surface and the elemental composition was determined by energy dispersive $X$-ray analysis (EDX). Microhardness was evaluated using the Vickers indentation test, and fluoriderelease was monitored with an ion-selective electrode.

\section{MATERI AL AND METHODS}

Ethical approval for this project was obtained on $1^{\text {st }}$ October 2014 by the Ethical Committee of Bezmiâlem Vakif University (reference number 71306642/050-01-04/282), which was performed according to the ethical standards laid down in the 1964 Declaration of Helsinki and its later amendments.

\section{Characterisation of UltraSeal XT ${ }^{\circledR}$ hydro"}

The composition of the UltraSeal $\mathrm{XT}^{\otimes}$ hydro ${ }^{\mathrm{TM}}$ sealant (Ultradent Products, South Jordan, Utah, USA) used in this study, as listed in the safety data sheet provided by the manufacture ${ }^{14}$, is given in Figure 1. Cylindrical polypropylene moulds of $7 \mathrm{~mm}$ diameter and $2 \mathrm{~mm}$ depth were filled with UltraSeal $\mathrm{XT}^{\circledR}$ hydro ${ }^{m}$ monomer solution that was light-cured for $20 \mathrm{~s}$ at $1000 \mathrm{mWcm}^{-2}$ (using a BA Optima 10 curing light, BA International Ltd., Northampton, Northamptonshire, UK). The resulting cured UltraSeal XT ${ }^{\circledR}$ hydro ${ }^{\text {"' }}$ discs were then characterised by FTIR, SEM, and EDX and their microhardness and fluoride-release behaviour were measured.

\section{Scanning electron microscopy and energy dispersive $\mathrm{X}$-ray analysis}

Fracture surfaces of UltraSeal $X^{\circledR}{ }^{\circledR}$ hydro $^{m}$ for SEM and EDX analysis were produced by crushing the cured discs between steel plates under a lowimpact force. Scanning electron microscopy was carried out on the fracture surfaces of uncoated samples attached to carbon tabs on a JEOL JSM5410 LV electron microscope with an Oxford Instruments X-MaxN EDX detector in low vacuum mode. All back-scattered and secondary electron images were obtained with an accelerating voltage of $1.0 \mathrm{kV}$ at a working distance of $8.4 \mathrm{~mm}$.

\section{Fourier transform infra-red spectroscopy}

The FTIR spectra of the unset UltraSeal $\mathrm{XT}^{\circledR}$ hydro ${ }^{\text {tm }}$ monomer solution and of the cured discs were obtained in triplicate using a Perkin Elmer Spectrum Two spectrometer with a Universal Diamond attenuated total reflectance attachment (Perkin Elmer, London, UK). Spectra were recorded with 16 accumulated scans between $4000 \mathrm{~cm}^{-1}$ and $450 \mathrm{~cm}^{-1}$ wavenumbers at a resolution of $4 \mathrm{~cm}^{-1}$.

The degree of conversion (DC) was estimated by comparing the ratios of the intensities of the FTIR peaks for the reactive polymerising $\mathrm{C}=\mathrm{C}$ bond (at $1637 \mathrm{~cm}^{-1}$ ) and the invariant $\mathrm{C}=\mathrm{O}$ bond (at 1717 $\mathrm{cm}^{-1}$ ) in the cured polymer and monomer using the following equation:

$\mathrm{DC}=\left(1-\left[\frac{([C=C] \text { in polymer }) /([C=0] \text { in polymer })}{([C=C] \text { in monomer }) /([C=0] \text { in monomer })}\right]\right) \times 100 \%$

\section{Fluoride ion release}

Three cured UltraSeal $\mathrm{XT}^{\oplus}$ hydro"m discs were individually placed in three polypropylene centrifuge tubes containing $5 \mathrm{~cm}^{3}$ of deionized water and stored

\begin{tabular}{|l|c|}
\hline \multicolumn{1}{|c|}{ Compound } & Quantity (wt\%) \\
\hline Triethylene glycol dimethacrylate (TEGDMA) & $<20$ \\
\hline Diurethane dimethacrylate (DUDMA) & $<8$ \\
\hline Aluminium oxide $\left(\mathrm{Al}_{2} \mathrm{O}_{3}\right)$ & $<4$ \\
\hline Methacrylic acid $(\mathrm{MAA})$ & $<1$ \\
\hline Titanium dioxide $\left(\mathrm{TiO}_{2}\right)$ & $<0.3$ \\
\hline Sodium monofluorophosphate $\left(\mathrm{Na}_{2} \mathrm{PO}_{3} \mathrm{~F}\right)$ & $<0.2$ \\
\hline
\end{tabular}

Figure 1- Composition of UltraSeal $\mathrm{XT}^{\circledR}$ hydro ${ }^{\mathrm{TM}}$ 
in the absence of light at $37^{\circ} \mathrm{C}$. The release of free fluoride ions from the cured discs was monitored daily throughout a 14-day period using an ionselective electrode (Cole-Parmer, London, UK) and Orion 4 Star meter (Thermo Fisher Scientific, East Grinstead, UK).

\section{Microhardness evaluation}

The Vickers microindentation test was carried out on 3 UltraSeal $\mathrm{XT}^{\circledR}{ }^{\circledR}$ hydro ${ }^{\text {tm }}$ discs using a Buehler Micromet Hardness Tester (Buehler, Coventry, Warwickshire, UK) with a load of $200 \mathrm{~g}$ and contact time of $2.5 \mathrm{~s}$. Three measurements were taken at random points on both sides of each sample disc. Indentation diagonals were measured in micrometres with the aid of a stereomicroscope and converted to Vickers hardness numbers (VHN) using conversion tables provided by Buehler, Coventry, Warwickshire, UK.

\section{Microleakage assessment}

Twenty sound extracted human molar teeth were obtained from patients with orthodontic or periodontal problems who had tendered their informed consent. The teeth were manually debrided with scaling instruments, cleaned with pumice paste and stored in distilled water for up to four weeks. The teeth were then randomly divided into two groups. A flow diagram for the experimental procedures is given in Figure 2.

The occlusal surfaces of Group I teeth $(n=10)$ were acid etched with $35 \%$ phosphoric acid gel (UltraSeal $\mathrm{XT}^{\circledR}$ hydro ${ }^{\mathrm{m}}$, Ultradent Products, South Jordan, Utah, USA) for $20 \mathrm{~s}$, rinsed and lightly air dried, as suggested by the manufacturer. The UltraSeal $\mathrm{XT}^{\circledR}{ }^{\circledR}$ hydro ${ }^{\mathrm{m}}$ sealant was then applied by the same operator, according to the manufacturer's instructions, and light cured for $20 \mathrm{~s}$ (using a BA Optima 10 curing light, BA International Ltd., Northampton, Northamptonshire, UK).

Group II teeth $(n=10)$ were sequentially subjected to laser ablation and acid etching. Laser conditioning of the occlusal surfaces of Group II teeth was carried out using a 2940 nm Er:YAG laser system (LightWalker ${ }^{\circledR}$, Fotona, Ljubljana, Slovenia). The Er:YAG laser energy was applied at a density

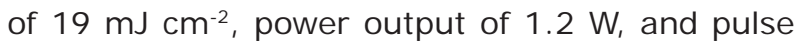
energy of $120 \mathrm{~mJ}$ using a $600 \mu \mathrm{m}$ diameter sapphire tip with a beam spot size of $0.63 \mathrm{~mm}^{2}$ at a working distance of $8 \mathrm{~mm}$ at an angle of $90^{\circ}$ under water cooling at $50 \mathrm{~cm}^{3} \mathrm{~min}^{-1}$. The lased teeth were rinsed with water, thoroughly air dried, acid etched (as outlined above), and then lightly air dried prior to sealing with UltraSeal $\mathrm{XT}^{\circledR}$ hydro ${ }^{\mathrm{m}}$.

Immediately after sealing, the teeth were placed in distilled water at $37^{\circ} \mathrm{C}$ for $24 \mathrm{~h}$ and then thermocycled 2500 times between 5 and $55^{\circ} \mathrm{C}$ with a transfer time of $10 \mathrm{~s}$ and a dwell time of 30 $\mathrm{s}$. The teeth were then coated with nail varnish, leaving a $2 \mathrm{~mm}$ window around the sealant, and the roots were embedded in an acrylic resin cylinder (Meliodent, Bayer Co., Leverkusen, Germany). Each sample was placed in $0.5 \%$ basic fuchsin dye solution for $24 \mathrm{~h}$, rinsed under flowing tap water for $5 \mathrm{~min}$ to remove excess dye, and sectioned in the bucco-lingual direction using a water-cooled diamond saw to obtain three slices. Each of the tooth sample slices was then examined twice under a stereomicroscope (SMZ 800, Nikon, Tokyo, Japan) at 20x magnification by two investigators who were unaware of the pre-treatment of each sample. The microleakage scoring criteria are listed in Figure $3^{1,9}$.

The microleakage data were analysed using the statistical package SPSS 14.0.0 for Windows (SPSS,

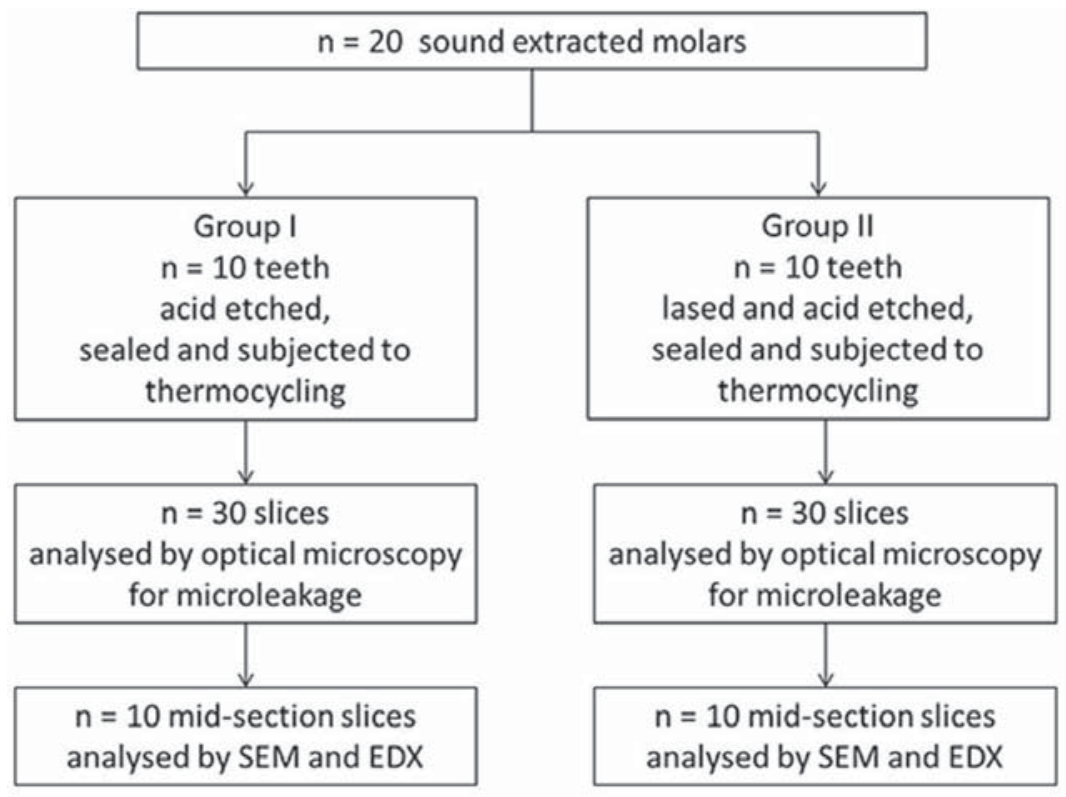

Figure 2- Flow diagram of experimental procedures 
Chicago, Illinois, USA). Significant differences were evaluated using the Mann-Whitney $U$ test $(p=0.05)$. I nter-examiner variability was analysed with the kappa statistic, which was found to be 0.9 , indicating high reproducibility.

\section{SEM and EDX analyses of sealed teeth}

SEM and EDX analyses were carried out on the middle slices of the sectioned teeth using uncoated samples attached to carbon tabs on a JEOL JSM5410 LV electron microscope with an Oxford Instruments X-MaxN EDX detector in low vacuum mode. All back-scattered electron images and EDX maps were obtained with an accelerating voltage of $20 \mathrm{kV}$ at a working distance of $20 \mathrm{~mm}$.

\section{RESULTS}

\section{SEM and EDX analyses}

Secondary electron images showing the topography of the fracture surfaces of light cured UltraSeal $\mathrm{XT}^{\circledR}{ }^{\circledR}$ hydro ${ }^{\mathrm{m}}$ are presented in Figures $4 \mathrm{a}$ and $4 \mathrm{~b}$. Angular filler fragments of up to $\sim 5$ $\mu \mathrm{m}$ in diameter are seen to be embedded in the polymerised matrix. The textured irregular surfaces observed arise from ductile fracture with associated plastic deformation.
Back-scattered electron images of the UltraSeal $\mathrm{XT}^{\circledR}$ hydro ${ }^{m}$ fracture surfaces (Figures $4 \mathrm{c}$ and $\mathrm{d}$ ) provide compositional information, since elements with higher atomic number scatter electrons more effectively and appear as brighter regions. These images also show a distribution of highly angular and fibrous submicron and nano-sized filler particles throughout the polymerised matrix.

The EDX analysis of a $100 \mu \mathrm{m}$ by $125 \mu \mathrm{m}$ window of a polished section of the light cured sealant indicated that this material is principally composed of carbon, oxygen, barium, silicon, aluminium, calcium, and phosphorus (Table 1). Individual EDX spot analyses of the filler particles showed that these phases comprise a mixture of silicon-, aluminium-, and barium-bearing minerals. Sodium was also noted at approximately 0.1 wt\%. The manufacturer's safety data sheet for UltraSeal $\mathrm{XT}^{\circledR}$ hydro $^{\mathrm{m}}$ (Figure $\mathrm{1}^{14}$ ) lists sodium monofluorophosphate $\left(\mathrm{Na}_{2} \mathrm{PO}_{3} \mathrm{~F}\right)$ at levels below 0.2 wt\%, which were found to be below the EDX detection limit for fluorine.

\section{FTI R spectroscopy}

The FTIR spectra of the monomeric UltraSeal $\mathrm{XT}^{\circledR}$ hydro ${ }^{\mathrm{m}}$ solution and light cured polymerised discs are shown in Figure 5, and the corresponding

\begin{tabular}{|c|c|}
\hline Score & Definition \\
\hline 0 & No dye penetration \\
\hline 1 & Dye penetration up to $1 / 2$ of the fissure \\
\hline 2 & Dye penetration beyond $1 / 2$ of the fissure without total involvement \\
\hline 3 & Dye penetration to the sealant-base \\
\hline
\end{tabular}

Figure 3- Microleakage scoring criteria
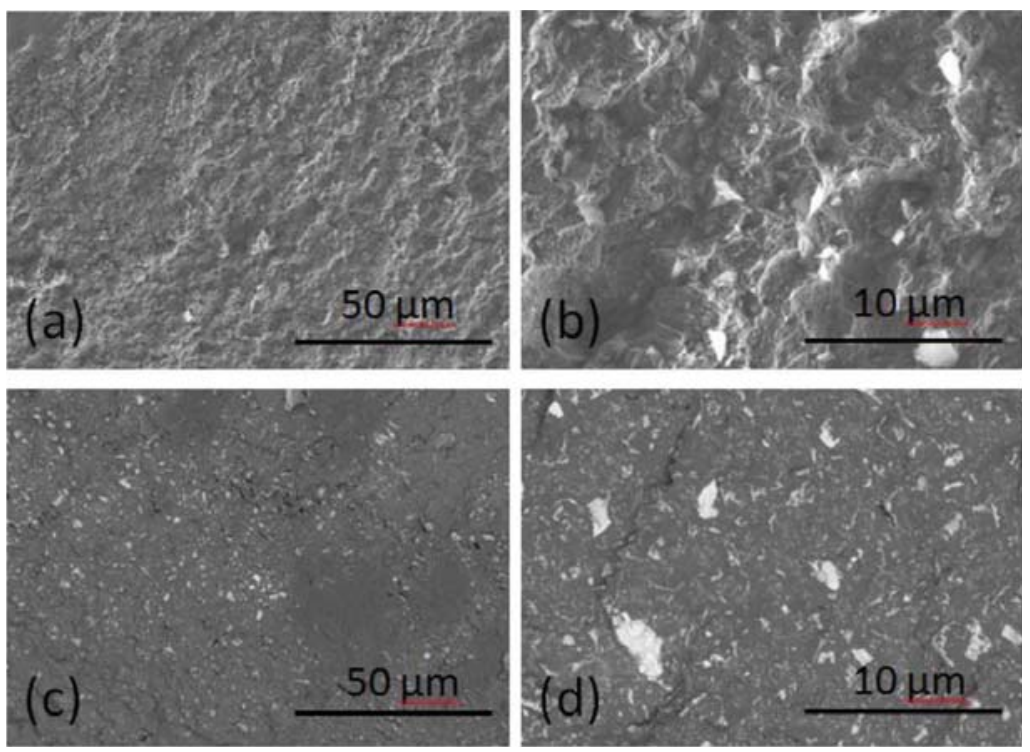

Figure 4- Fracture surfaces of UltraSeal $\mathrm{XT}^{\circledR}{ }^{\circledR}$ hydro ${ }^{\mathrm{TM}}$ as $(\mathrm{a}, \mathrm{b})$ secondary electron images and (c,d) back-scattered electron images 
functional group assignments are listed in Figure $6{ }^{15}$. According to the manufacturer's safety data sheet (Figure $1^{14}$ ), the organic component of UltraSeal $\mathrm{XT}^{\circledR}$ hydro ${ }^{\mathrm{m}}$ comprises a mixture of triethylene glycol dimethacrylate (TEGDMA), diurethane dimethacrylate (DUDMA), and methacrylic acid (MAA). Present in these monomers are hydrophilic carboxylic acid (-COOH), secondary amine $(-\mathrm{NH})$ and carbonyl $(-\mathrm{C}=\mathrm{O})$ groups, hydrophobic alkane $\left(-\mathrm{CH}_{3}\right)$ and alkene $\left(-\mathrm{C}=\mathrm{CH}_{2}\right)$ groups, and ether (-C-O-C-) groups, which are of amphiphilic character. Each of these functional groups appears in the FTIR spectra of both the unset UltraSeal $\mathrm{XT}^{\circledR}$ hydro ${ }^{\mathrm{m}}$ solution and light cured polymerised discs (as indicated in Figure 5). In addition to these groups, aromatic carbon-carbon stretching vibrations are also present in the FTIR spectra of both unset and light cured UltraSeal $\mathrm{XT}^{\circledR}{ }^{\circledR}$ hydro ${ }^{\mathrm{TM}}$, which indicate the presence of undisclosed aromatic monomer and/or initiator compounds within the mixture.

The very broad compound signal centred at approximately $1000 \mathrm{~cm}^{-1}$ wavenumbers in the unset and light cured FTIR spectra of the sealant arises from various $\mathrm{Si}-\mathrm{O}$ and $\mathrm{Al}-\mathrm{O}$ stretching modes of the silicon- and aluminium-bearing mineral filler phases.

The degree of conversion of resin-based sealants

Table 1- Elemental composition of UltraSeal $\mathrm{XT}^{\circledR}$ hydro ${ }^{\mathrm{TM}}$

\begin{tabular}{cccccccc}
\hline Element & $\mathbf{C}$ & $\mathbf{O}$ & $\mathbf{B a}$ & Si & Al & Ca & P \\
\hline Mass* $(w t \%)$ & 44 & 30 & 9.6 & 7.7 & 4.7 & 2.4 & 1.8 \\
\hline
\end{tabular}

${ }^{*}$ Relative standard deviations are less than $2 \%$ in each case

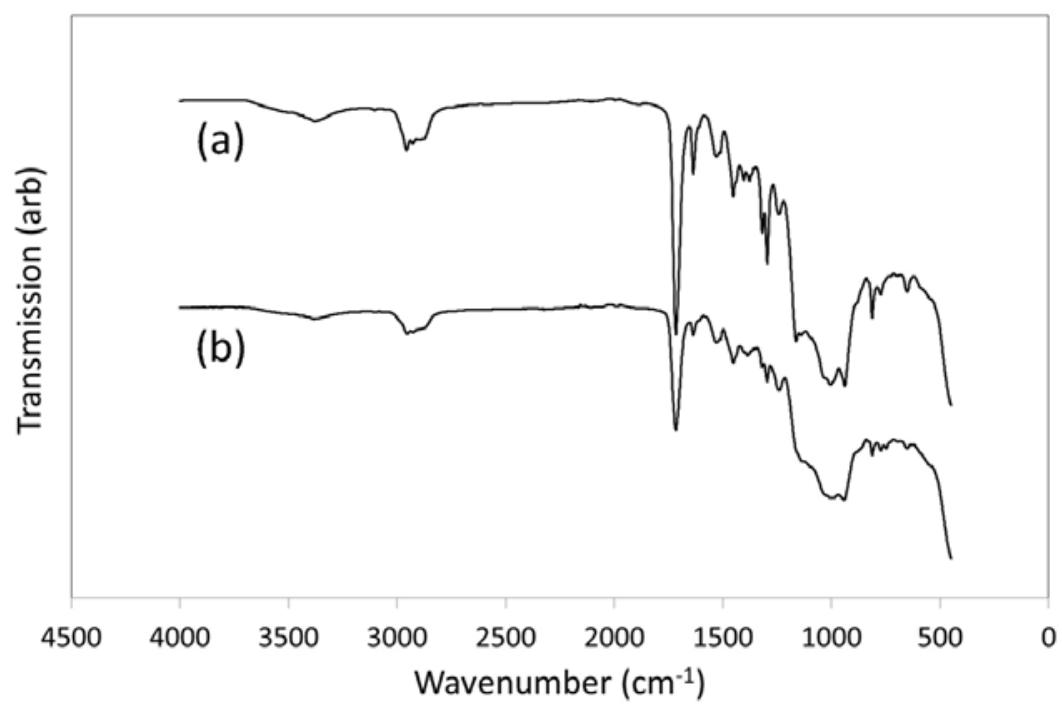

Figure 5- FTIR spectra of (a) unset UltraSeal $\mathrm{XT}^{\circledR}$ hydro $^{\mathrm{TM}}$ and (b) light-cured UltraSeal $\mathrm{XT}^{\circledR}$ hydro $^{\mathrm{TM}}$

\begin{tabular}{|l|c|c|}
\hline \multicolumn{1}{|c|}{ Wavenumber $\left(\mathbf{c m}^{-1}\right)$} & Functional group & Compound \\
\hline 3,380 & OH and $\mathrm{NH}$ stretch & MAA, DUDMA \\
\hline 2,950 & C-H stretch & MAA, DUDMA, TEGDMA \\
\hline 1,717 & C=O stretch & MAA, DUDMA, TEGDMA \\
\hline $1,637,1,610$ & C=C stretch & MAA, DUDMA, TEGDMA \\
\hline $1,530,1,450$ & C-C aromatic stretch & Unassigned \\
\hline $1,403,1,386,1,370$ & C-H bend & MAA, DUDMA, TEGDMA \\
\hline $1,320,1,296$ & C-O stretch & MAA, DUDMA, TEGDMA \\
\hline 1,240 & C-H bend & MAA, DUDMA, TEGDMA \\
\hline 1,000 & Si-O and Al-O stretch & Mineral filler phases \\
\hline 812 & C=C twist & MAA, DUDMA, TEGDMA \\
\hline $770-650$ & Various C-H bend & MAA, DUDMA, TEGDMA \\
\hline
\end{tabular}

Figure 6- Functional group assignments for the FTIR spectra of un-cured and cured UltraSeal $\mathrm{XT}^{\circledR}$ hydro $^{\mathrm{TM}}$ 
Table 2- Microleakage scores as functions of enamel conditioning

\begin{tabular}{cccccc}
\hline Microleakage score & $\mathbf{0}$ & $\mathbf{1}$ & $\mathbf{2}$ & $\mathbf{3}$ & *Significance \\
\hline Group I (Acid) & 17 & 3 & 5 & 5 & $\mathrm{a}$ \\
Group II (Laser and acid) & 29 & 1 & 0 & 0 & $\mathrm{~b}$ \\
\hline
\end{tabular}

*Different letters indicate significant differences $(p<0.001)$

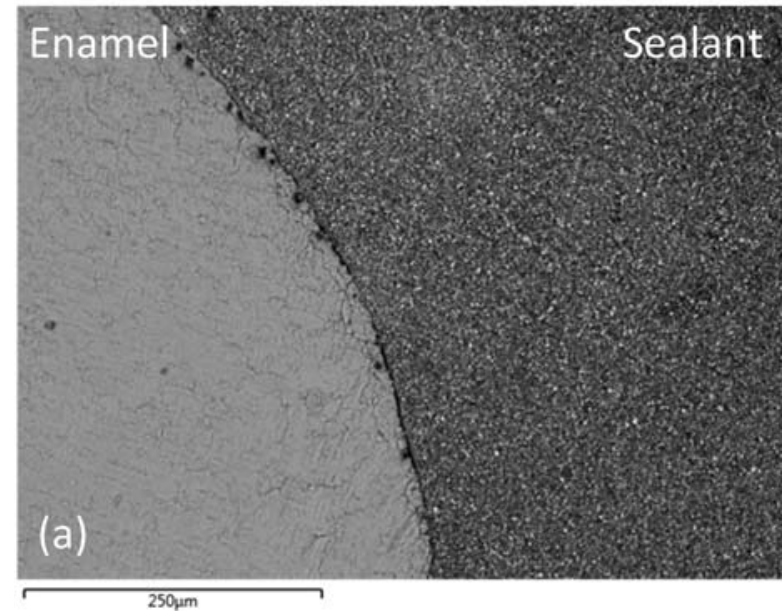

C K series

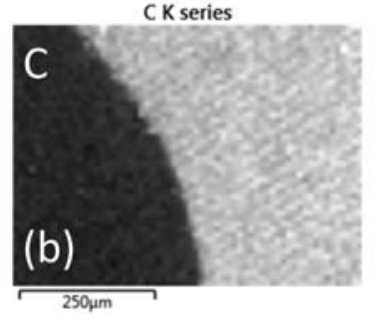

Si K series

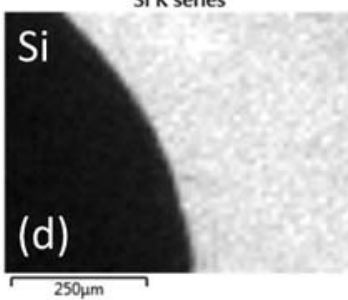

Ba L series

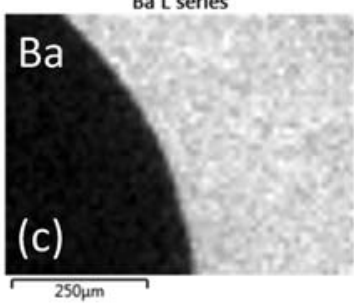

Al K series

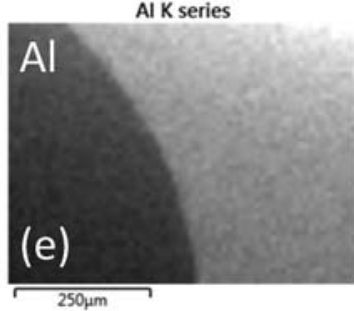

Figure 7- (a)- Back-scattered scanning electron microscopy image of UltraSeal $\mathrm{XT}^{\circledast}$ hydro ${ }^{\mathrm{TM}}$ in contact with acid-etched enamel and corresponding EDX maps of (b) carbon, (c) barium, (d) silicon, and (e) aluminium

is defined as the percentage of acrylate $\mathrm{C}=\mathrm{C}$ groups from the various monomers that have undergone polymerisation ${ }^{7}$. The mechanical, physical, and chemical integrity and clinical performance of the cured sealant are strongly dependent upon this property. Analysis of the FTIR spectra of unset and light cured UltraSeal $\mathrm{XT}^{\circledR}$ hydro ${ }^{\mathrm{m}}$ indicated that this sealant achieved a degree of conversion of $50.6 \pm 2.2 \%$ under the selected experimental conditions.

\section{Fluoride ion release}

Light cured UltraSeal $\mathrm{XT}^{\circledR}$ hydro ${ }^{\mathrm{m}}$ discs failed to release any detectible free fluoride ions into deionised water during a 14-day observation period, indicating that any fluoride ion release was at a concentration below $0.001 \mathrm{ppm}$. According to the manufacturer's safety data sheet (Figure $1^{14}$ ), the level of sodium monofluorophosphate $\left(\mathrm{Na}_{2} \mathrm{PO}_{3} \mathrm{~F}\right)$ in UltraSeal $\mathrm{XT}^{\circledR}$ hydro $^{\mathrm{m}}$ is lower than $0.2 \mathrm{wt} \%$. This corresponds with a maximum fluoride ion concentration within the sealant of 0.0264 wt\%.

\section{Microhardness}

Microhardness provides a measure of the resistance of a sealant to plastic deformation under applied compressive forces. The Vickers hardness number (VHN) of light cured UltraSeal $\mathrm{XT}^{\circledR}$ hydro ${ }^{\mathrm{mm}}$ was found to be $24.2 \pm 1.5$.

\section{Microleakage assessment}

The distributions of microleakage scores for the acid etched (Group I) and sequentially lased and acid etched (Group II) teeth are listed in Table 2. Thirteen of the Group I teeth sections exhibited microleakage with maximum dye penetration to the sealant base; whereas, only one Group II tooth section demonstrated microleakage within the upper half of the fissure. These data indicate that the application of Er:YAG laser ablation under the selected experimental conditions prior to acid etching significantly improves the in vitro resistance of the sealed teeth to microleakage $(p<0.001)$.

\section{SEM and EDX analyses of sealed teeth}

Back-scattered electron images of the enamelsealant interfaces of acid etched (Group I) and sequentially lased and acid etched (Group II) teeth are shown in Figures 7a and 8a. Enhanced surface roughness on a 50 to $100 \mu \mathrm{m}$ scale was observed for the enamel surfaces that had been preconditioned with the Er:YAG laser. This observation confirms those of other studies which report enhanced surface roughness of up to $155 \mu \mathrm{m}$ for laser conditioned teeth ${ }^{1,9}$. The filler within the sealant was observed to remain homogeneously distributed when the material was placed in contact with the acid etched enamel surface; however, the enhanced surface roughness of the lased teeth caused the segregation and concentration of the filler particles at the enamel-sealant interface. Corresponding elemental carbon, barium, silicon, and aluminium EDX maps of the sealed Group I and II teeth are presented in Figures $7(b, c, d, e)$ and $8(b, c, d, e)$, 


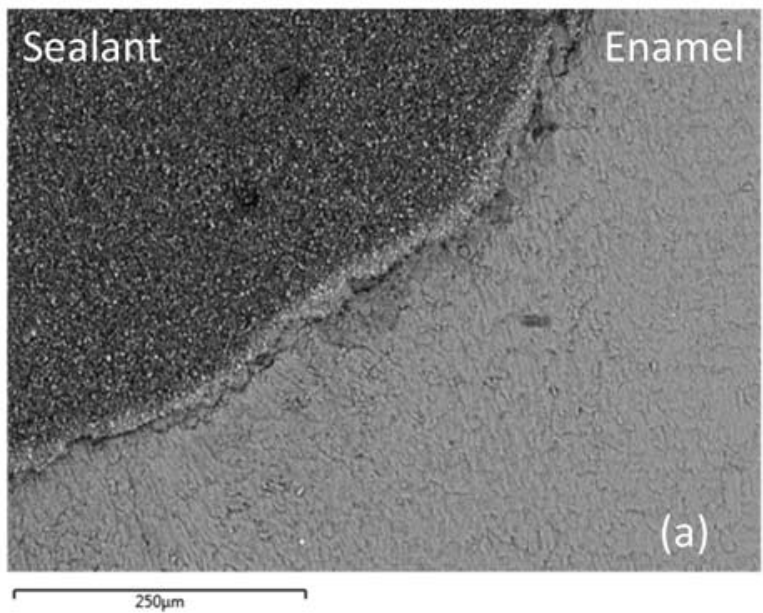

$\mathrm{CKa1} 2$

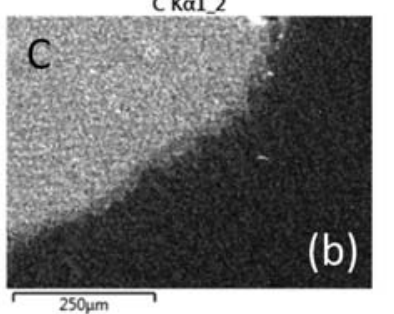

Si Ka1

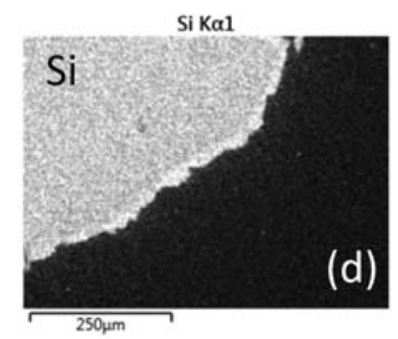

(d)

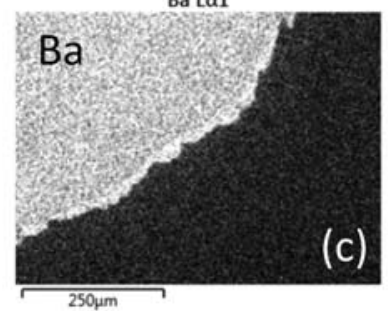

Al Ka1

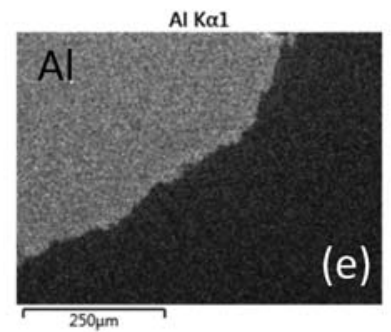

Figure 8- (a) Back-scattered scanning electron microscopy image of UltraSeal $\mathrm{XT}^{\oplus}$ hydro ${ }^{\mathrm{TM}}$ in contact with sequentially lased and acid etched enamel and corresponding EDX maps of (b) carbon, (c) barium, (d) silicon, and (e) aluminium

respectively. These images highlight the zoning of the barium-, silicon-, and aluminium-bearing mineral phases at the enamel-sealant interface of the lased teeth.

\section{DISCUSSION}

\section{Characterisation}

Scanning electron microscopy with EDX analysis of fracture surfaces of UltraSeal $X^{\circledR}{ }^{\circledR}$ hydro ${ }^{\mathrm{TM}}$ demonstrated that this sealant is a ductile material that is highly filled with uniformly distributed micrometre and nanometre sized silicon-, aluminium-, and barium-bearing mineral phases. This finding contradicts the information contained in the manufacturer's safety data sheet that indicates that this sealant contains aluminium and titanium oxides and does not list constituent silicon- and barium-bearing mineral phases (Figure 1$)^{14}$. It should be noted that, despite the manufacturer's claim, no titanium phases were detected in the sealant by EDX analysis.

The curing efficiency of this sealant, $\sim 51 \%$, appears towards the lower end of the range $(\sim 50$ to $76 \%$ ) reported for contemporary commercially available resin-based fissure sealants cured under similar experimental conditions ${ }^{6,11}$. It is considered that the high level of inorganic mineral filler in UltraSeal $\mathrm{XT}^{\circledR}{ }^{\circledR}$ hydro ${ }^{\mathrm{m}}$ may impact the degree of cure by inhibiting light penetration and also by presenting a physical barrier to monomer crosslinking.

The microhardness of UltraSeal $\mathrm{XT}^{\circledR}$ hydro ${ }^{\mathrm{Tm}}$ (VHN $\sim 24$ ) was found to fall within the range reported for commercial resin-based sealants (VHN from $\sim 9$ to 75$)^{2,6,11}$. In general, despite the reduced curing efficiency of highly filled resin-based sealants, microhardness tends to increase with increasing filler-content ${ }^{11}$. In this respect, submicron and nano-sized fillers, such as those present in this sealant, are regarded to be particularly effective in increasing microhardness and reducing plastic deformation under occlusal forces ${ }^{11}$.

Any fluoride species present in UltraSeal $\mathrm{XT}^{\circledR}$ hydro ${ }^{m}$ were found to be below the detection limits of both the EDX instrument and the ion-selective electrode. In contrast, during a 30-day period under similar experimental conditions, other commercially available resin-based fissure sealants are reported to release up to $58 \mu \mathrm{g} \mathrm{cm}^{-2}$ of free fluoride ions ${ }^{11}$. However, these reported levels of fluoride release are unlikely to be significant regarding any beneficial impact on acid- and caries-resistance of local enamel, and, in this respect, the lack of detectible fluoride release from UltraSeal $\mathrm{XT}^{\circledR}{ }^{\circledR}$ hydro ${ }^{\mathrm{TM}}$ is not regarded to be a comparative disadvantage.

\section{Microleakage}

Data obtained under the selected experimental parameters in this study indicate that laser ablation prior to conventional acid etching significantly improves the in vitro resistance of the sealed teeth to microleakage (Table 2). The superior resistance to microleakage of the lased teeth is attributed to the enhanced roughness of the ablated enamel surfaces. This finding confirms that of Khogli, et al. ${ }^{10}$ (2013) who investigated the impact of laser ablation as an adjunct to acid etching to precondition molars prior to sealing with a filled hydrophilic sealant. Other studies, however, report that lasing prior to acid etching provides no statistically significant improvement in resistance to microleakage ${ }^{3,5}$. This lack of consensus on the effectiveness of Er:YAG laser ablation prior to acid etching is likely to arise from the range of laser settings employed by various researchers and the suitability of different sealants to the lased enamel surfaces ${ }^{3,5,10}$.

The principal mode of adhesion of resin-based 
fissure sealants to enamel is via the formation of micromechanically interlocking tags that penetrate the macro- and micro-porosities presented by the preconditioned enamel. Very little physicochemical interaction exists between the high energy surface of the hydroxyapatite in enamel and the organic constituents of the sealant ${ }^{13}$.

Enamel preconditioning by etching with phosphoric acid gel is currently the most common method used to prepare the occlusal tooth surface to receive the fissure sealant. This method of etching may not prove entirely effective on aprismatic enamel located at the fissure entrance and in the presence of remnant pellicle biofilm and organic debris lodged in deep narrow fissures ${ }^{1,5,9}$. Potential advantages of laser ablation prior to acid etching are reported to be: enhanced roughness and wettability of the lased enamel surface; more effective removal of pellicle and debris; superior conditioning of aprismatic hydroxyapatite; and enhanced acidresistance of lased enamel ${ }^{5,9}$. Disadvantages of laser conditioning include the potential vitrification of the enamel surface at subablative laser energies and excessive roughness and microcracking under extreme ablation ${ }^{5,12}$. Laser conditioning of enamel is a relatively recent technique and further research is required to optimise the operating parameters.

It is conjectured that the more viscous fissure sealants may fail to flow readily and fully adapt to the rougher surfaces presented by lased enamel ${ }^{10}$. In addition, this study has demonstrated that inorganic filler particles within a sealant may partially separate out from the resin phase and congregate at the interface as it flows over the rough lased surface. It is not presently known whether this congregation of filler particles at the interface of lased enamel will have a detrimental impact on the long-term clinical performance of the sealant.

At present, all commercial resin-based fissure sealants are designed for acid etched enamel. It is suggested that, to take full advantage of the potential benefits of laser conditioning, a new generation of fissure sealants, which are specifically tailored to adhere and adapt to lased enamel, is required.

\section{CONCLUSI ONS}

The purpose of this study was to characterise the new resin-based hydrophilic fissure sealant, UltraSeal $\mathrm{XT}^{\circledR}{ }^{\circledR}$ hydro ${ }^{\mathrm{TM}}$ (Ultradent Products, USA), and to investigate its in vitro resistance to microleakage after placement on conventionally acid etched and sequentially lased and acid etched molars.

Scanning electron microscopy and energy dispersive X-ray analysis of fracture and polished surfaces indicated that UltraSeal $\mathrm{XT}^{\oplus}$ hydro $^{\mathrm{TM}}$ comprises irregular submicron and nano-sized silicon-, barium-, and aluminium-bearing filler phases embedded in a ductile resin matrix. Under standard light curing, UltraSeal $\mathrm{XT}^{\circledR}$ hydro ${ }^{\mathrm{TM}}$ achieved a degree of conversion $(50.6 \pm 2.2 \%)$ and a Vickers microhardness (24.2 \pm 1.5$)$ towards the lower end of the reported ranges for other commercial acrylate-based fissure sealants.

Laser preconditioning was found to significantly decrease microleakage and to increase enamel surface roughness, which caused zoning of the filler particles at the enamel-sealant interface.

\section{REFERENCES}

1- Baygin O, Korkmaz FM, Tüzüner T, Tanriver M. The effect of different enamel surface treatments on the microleakage of fissure sealants. Lasers Med Sci. 2012;27: 153-60.

2- Beun S, Bailly C, Devaux J, Leloup G. Physical, mechanical and rheological characterization of resin-based pit and fissure sealants compared to flowable resin composites. Dent Mater. 2012; 28: 349-59.

3- Borsatto MC, Corona SA, Palma-Dibb RG, Ramos RP, Pécora JD. Microleakage of a resin sealant after acid-etching, Er: YAG laser irradiation and air-abrasion of pits and fissures. J Clin Laser Med Surg. 2001; 19(2): 83-7.

4- Brinker SP. Preventing carious lesions. Clinical steps for applying a newly introduced hydrophilic sealant. Dent Today. 2013; 32:82-3. 5- Ciucchi P, Neuhaus KW, Emerich M, Peutzfeldt A, Lussi A. Evaluation of different types of enamel conditioning before application of a fissure sealant. Lasers Med Sci. 2015;30:1-9.

6- Eliades A, Birpou E, Eliades T, Eliades G. Self-adhesive restoratives as pit and fissure sealants: a comparative laboratory study. Dent Mater. 2013;29:752-62.

7- Ferracane JL. Correlation between hardness and degree of conversion during the setting reaction of unfilled dental restorative resins. Dent Mater. 1985; 1:11-4.

8- Gooch BF, Griffin SO, Gray SK, Kohn WG, Rozier RG, Siegal $M$, et al. Preventing dental caries through school-based sealant programs: updated recommendations and reviews of evidence. J Am Dent Assoc. 2009; 140: 1356-65.

9- Hossain M, Yamada Y, Masuda-Murakami Y, Nakamura Y. Removal of organic debris with Er:YAG laser irradiation and microleakage of fissures sealants in vitro. Lasers Med Sci. 2012; 27:895-902.

10- Khogli AE, Cauwels R, Vercruysse C, Verbeeck R, Martens $\mathrm{L}$. Microleakage and penetration of a hydrophilic sealant and a conventional resin-based sealant as a function of preparation techniques: a laboratory study. Int J Paediatr Dent. 2013;23:1322.

11- Kuşgöz A, Tüzüner T, Ülker M, Kemer B, Saray O. Conversion degree, microhardness, microleakage and fluoride release of different fissure sealants. J Mech Behav Biomed Mater. 2010; 3: 594-9.

12- Moshonov J, Stabholz A, Zyskind D, Sharlin E, Peretz B. Acidetched and erbium: yttrium aluminium garnet laser-treated enamel for fissure sealants: a comparison of microleakage. Int J Paediatr Dent. 2005; 15:205-9.

13- Sezinando A. Looking for the ideal adhesive - a review. Rev Port Estomatol Med Med Dent Cir Maxilofac. 2014; 55: 194-206. 14- Ultradent Products, Inc. Safety Data Sheet: UltraSeal XT ${ }^{\circledR}$ hydroTM [Internet]. South J ordan: Ultradent Products Inc.; 2015 [cited March 31 2016]. Available from: https://www.ultradent. com/eu/MSDS/UltraSeal\% 20XT\% 20hydro.pdf

15- Williams DH, Fleming I. Spectroscopic methods in organic chemistry. $5^{\text {th }}$ ed. Maidenhead: McGraw-Hill; 1995. 